\title{
Isolation and identification of desert habituated arbuscular mycorrhizal fungi newly reported from the Arabian Peninsula
}

\author{
Sarah SYMANCZIK ${ }^{1}$, Janusz BŁASZKOWSKI ${ }^{2}$, Sally KOEGEL ${ }^{1}$, Thomas BOLLER ${ }^{1}$, Andres WIEMKEN ${ }^{1}$, \\ Mohamed N AL-YAHYA'EI ${ }^{1,3,4 *}$ \\ ${ }^{1}$ Zurich Basel Plant Science Center, Institute of Botany, University of Basel, Basel CH-4056, Switzerland; \\ ${ }^{2}$ Department of Plant Protection, West Pomeranian University of Technology, Szczecin PL-71434, Poland; \\ ${ }^{3}$ Soil and Water Research Center. Ministry of Agriculture and Fisheries, Al Khod 121, Sultanate of Oman; \\ ${ }^{4}$ Department of Aridland Agriculture, College of Food and Agriculture, United Arab Emirates University, Al Ain 15551, United \\ Arab Emirates
}

\begin{abstract}
Arbuscular mycorrhizal fungi (AMF) are known to facilitate the growth and vigour of many plants, particularly in arid ecosystems. In a survey of AMF in a date palm plantation and two natural sites of a desert in Oman, we generated many single spore-derived cultures of AMF. We identified a number of these isolates based on spore morphotyping and molecular phylogenetic analysis using the sequence of the LSU-rDNA. Here, we presented the characteristics of four species of AMF recovered, namely Claroideoglomus drummondii, Diversispora aurantia, Diversispora spurca and Funneliformis africanum. The four species have been described previously, but for the Arabian Peninsula they are reported here for the first time. Our endeavor of isolation and characterization of some AMF habituated to arid sites of Arabia represents a first step towards application for environmental conservation and sustainable agriculture in this region.
\end{abstract}

Keywords: arbuscular mycorrhizal fungi; biotechnology; isolation; characterization; desert ecosystem; Arabian Peninsula; Oman

Citation: Sarah SYMANCZIK, Janusz BŁASZKOWSKI, Sally KOEGEL, Thomas BOLLER, Andres WIEMKEN, Mohamed N AL-YAHYA'EI. 2014. Isolation and identification of desert habituated arbuscular mycorrhizal fungi newly reported from the Arabian Peninsula. Journal of Arid Land, 6(4): 488-497. doi: 10.1007/s40333-014-0021-9

Arbuscular mycorrhizal fungi (AMF) are well known to convey multiple benefits for plant growth and health in stressful environments (Newsham et al., 1995; Smith and Read, 2008). Under arid conditions, for example, mycorrhizal plants were found to maintain higher drought tolerance (Augé, 2001) and to have better access to phosphorus than non-mycorrhizal ones (Neumann and George, 2004). AMF may also enhance soil aggregate stability (Rillig and Mummey, 2006), a feature of particular relevance for the sandy soils prone to erosion.

Under the extreme conditions of desert ecosystems, AMF are believed to play an important role for the prospering of vegetation. Inoculation with AMF, for example, was found to improve water and nutrient uptake of desert succulents (Cui and Nobel, 1992), promote the desert tree Prosopis cineraria and thereby restore soil fertility by increasing soil organic carbon (Mathur and Vyas, 1995), enhance growth of the desert ephemeral plant Plantago minuta (Zhang et al., 2011) and the productivity of Plantago ovata, a cash crop in arid and semiarid regions (Mathur et al., 2006) and, furthermore, have the potential to contribute to conservation efforts for endangered tree species (Panwar and Vyas, 2002; Shen and Wang, 2011).

The diversity of AMF has been investigated in

*Corresponding author: Mohamed N AL-YAHYA'EI (E-mail: mohamed.yahyaei@uaeu.ac.ae)

The first and second authors contributed equally to this work.

Received 2013-06-19; revised 2013-10-16; accepted 2013-12-10

(C) Xinjiang Institute of Ecology and Geography, Chinese Academy of Sciences, Science Press and Springer-Verlag Berlin Heidelberg 2014 
many desert ecosystems of the world (Kiran et al., 1989; Jacobson, 1997; Stutz et al., 2000; Błaszkowski and Czerniawska, 2006; Uhlmann et al., 2006; Shi et al., 2007; Błaszkowski, 2012). One of the areas that have been neglected with respect to AMF until recently is the Arabian Peninsula. Our morphological and molecular analyses revealed unique communities of AMF in this area (Al-Yahya'ei et al., 2011). This uniqueness may be attributed to the particularity of the studied ecosystems. Geological history and the influence of past climates of this area (Preusser et al., 2002) have played a major role in shaping its unique and harsh environmental settings (Fisher and Membery, 1998; Glennie and Singhvi, 2002).

In the current study, we combined further biodiversity explorations with the establishment of a single-species culture collection of typical AMF of this region. Such a collection is crucially needed as a basis for various basic and applied researches. AMF can be applied as a biotechnological tool (Gianinazzi et al., 2002) to promote sustainable agriculture and environmental conservation. As recently summarized, strains of AMF isolated from such sites are likely well-adapted ecotypes, and they may have unique physiological capabilities to cope with the extreme conditions prevailing in the desert, such as long drought seasons leading to desiccation, extreme heat and low availability of soil nutrients during summer (Antunes et al., 2011). Therefore, these isolates might exhibit optimal performance in their original climate (Caravaca et al., 2003; Calvente et al., 2004; Marulanda et al., 2007).

Here, we used morphological and molecular identification techniques to characterize a part of the successfully cultured single-spore derived isolates of AMF, namely those which have obvious affinities to well-described species.

\section{Materials and methods}

\subsection{Study area}

The study area occurs in the northern territory of the Sultanate of Oman (Fig. 1a). The area is characterized by hyper-aridity (UNEP, 2006) with an annual rainfall which does not exceed $100 \mathrm{~mm}$ (Fisher and Membery, 1998) and high summer temperatures exceeding $48^{\circ} \mathrm{C}$ (Glennie and Singhvi, 2002). The four species of AMF described here were recovered from one or more of three distinct sites (i) a date palm (Phoenix dactylifera) plantation in the oasis of Al-Kamel $\left(22^{\circ} 12^{\prime} 56^{\prime \prime} \mathrm{N}\right.$, $\left.59^{\circ} 12^{\prime} 9 " \mathrm{E}\right)$ (Fig. 1b), (ii) a natural, undisturbed site $\left(22^{\circ} 14^{\prime} 11^{\prime \prime N}, 59^{\circ} 10^{\prime} 53 " \mathrm{E}\right)$ (Fig. 1c) with Tetraena qatarensis Beier \& Thulin. (previously Zygophyllum qatarense), Salvadora persica Wall., Prosopis cineraria (L.) Druce, and an inter-plant area (IPA) where dispersed patches of dry grass were apparently growing after rainfall, and (iii) a sand dune site $\left(21^{\circ} 52^{\prime} 39^{\prime \prime} \mathrm{N}, 5^{\circ} 52^{\prime} 44^{\prime \prime} \mathrm{E}\right)$ in the Al-Sharqiya Sands (Fig. 1d) with scattered Heliotropium kotschyi Gürke. More detailed information about the characteristics of the three sites was given in Al-Yahya'ei et al. (2011).

\subsection{Sampling, establishment and growth of trap and single-species cultures}

Four replicate plots of $200 \mathrm{~m}^{2}$ were randomly chosen at each site. From each plot, four plants of each species were selected for obtaining a pooled sample per plant species. The collection of soil and root samples and the procedure to establish the initial trap cultures have been described previously (Al-Yahya'ei et al., 2011).

The spores used for the morphological characterization were obtained from single-spore derived cultures established by the previously described pipette-tip procedure (Tchabi et al., 2010), starting with single spores isolated from the initial trap cultures. The cultures were maintained for six months using a consortium of the following host plants for AMF: Allium porrum L., Hieracium pilosella L. and Plantago lanceolata $\mathrm{L}$.

\subsection{Spore extraction}

Spores were extracted by wet sieving and sucrose density gradient centrifugation, using a modification of the method of Daniels and Skipper (1982). For each of the single-spore derived cultures, around $10 \mathrm{~mL}$ of harvested substrate were well suspended in $20 \mathrm{~mL}$ of water in a $50 \mathrm{~mL}$ Falcon tube. A $25-\mathrm{mL}$ sucrose solution $(70 \%, v / w)$ was injected to the bottom of the tube, forming a stepped density gradient that was centrifuged at $900 \mathrm{~g}$ for $2 \mathrm{~min}$. Spores of AMF were collected from the interface of sucrose solution, washed with tap water on a 32- $\mu \mathrm{m}$ sieve for 2 min, and transferred to Petri dishes. Spores were then picked individually under a stereomicroscope and either examined morphologically or used to extract DNA for molecular analysis. 

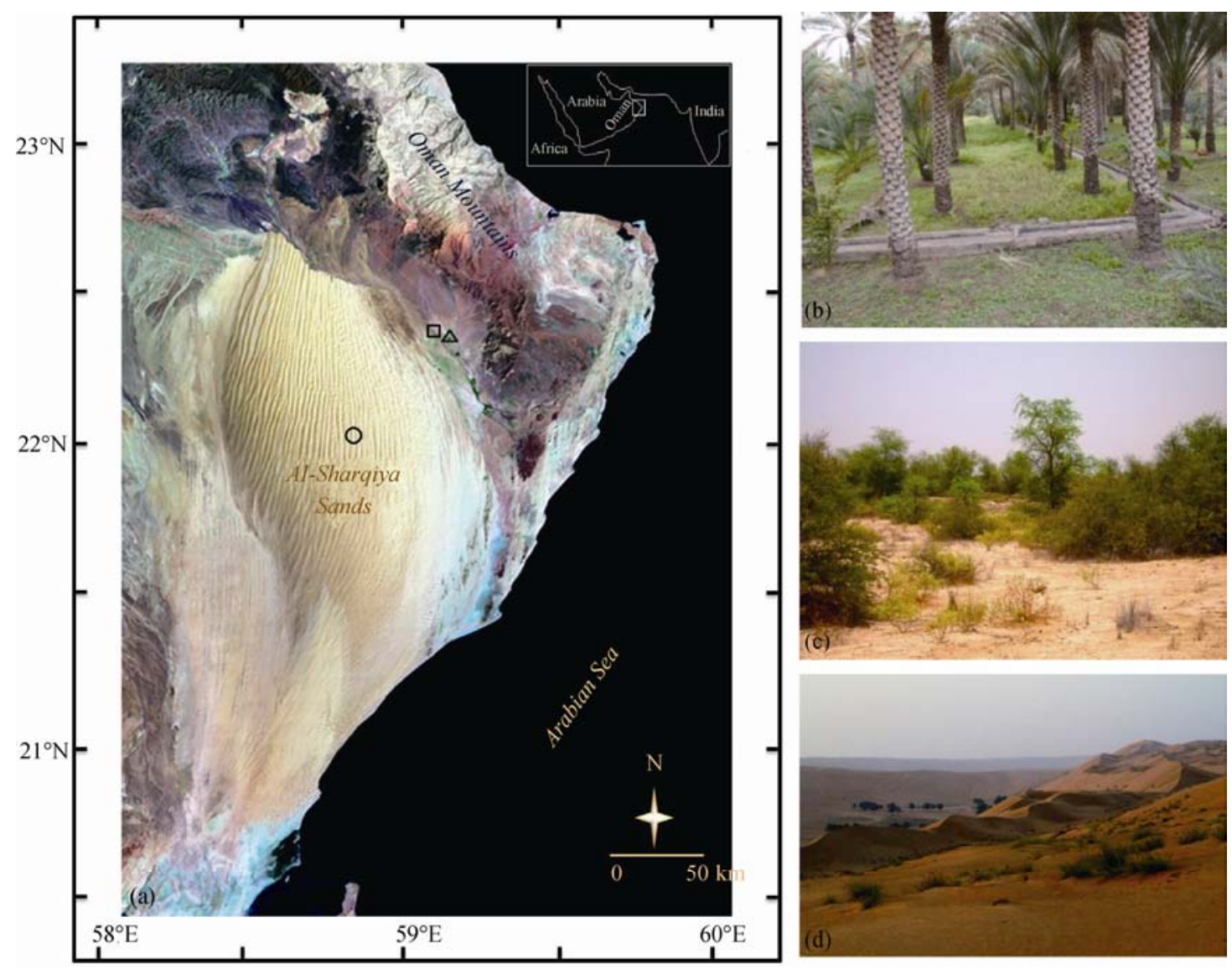

Fig. 1 The geography of the area and the explored sites. (a) Satellite image (Landsat TM RGB 742 courtesy of the U.S. Geological Survey) of Southern Arabia showing main geographical features of the area. Symbols correspond to sites depicted in (b)-(d). (b) Traditional date palm plantation (for site, see triangle on Fig.1a). (c) Natural undisturbed site (square on Fig.1a) with Tetraena qatarensis, Salvadora persica and Prosopis cineraria and interspersed patches of dry grasses. (d) Typical sand dune site in the region of Al-Sharqiya Sands (circle on Fig. 1a) where Heliotropium kotschyi occurs.

\subsection{Microscopy identification}

We determined the morphological characteristics of spores including their wall structure based on examination of at least 100 spores mounted either in water, lactic acid, polyvinyl alcohol/lactic acid/glycerol (PVLG) (Omar et al., 1979) or in a mixture (1:1, v/v) of PVLG and Melzer's reagent (water, iodine, potassium iodide). Spores at all developmental stages were crushed to varying degrees by applying pressure to the cover slip and then stored at $65^{\circ} \mathrm{C}$ for $24 \mathrm{~h}$ to clear their contents from oil droplets. They were then examined under an Olympus BX 50 compound microscope equipped with Nomarski differential interference contrast optics. Microphotographs were recorded on a Sony 3-CDD color video camera coupled with the microscope.

Voucher specimens were mounted in PVLG and a mixture of PVLG and Melzer's reagent $(1: 1, \mathrm{v} / \mathrm{v})$ on slides and deposited in the Soil and Water Research Center, Ministry of Agriculture and Fisheries, Sultanate of Oman; Institute of Botany, University of Basel, Switzerland; Department of Plant Protection (DPP), West Pomeranian University of Technology, Szczecin, Poland; and in the herbarium at Oregon State University (OSC) in Corvallis, Oregon, USA.

\subsection{Molecular analyses and phylogeny}

DNA was extracted by crushing single spores with a pipette tip in a $0.2 \mathrm{~mL}$ PCR tube containing $2 \mu \mathrm{L}$ of $0.25 \mathrm{M} \mathrm{NaOH}$. The tubes were incubated in a T3 Thermocycler (Biometra GmbH, Goettingen, Germany) at $95^{\circ} \mathrm{C}$ for $2 \mathrm{~min}$ before $1 \mu \mathrm{L}$ of $0.5 \mathrm{M}$ Tris $\mathrm{HCl}(\mathrm{pH}$ 8.0) and $2 \mu \mathrm{L}$ of $0.25 \mathrm{M} \mathrm{HCl}$ were added and incubated again at $95^{\circ} \mathrm{C}$ for $2 \mathrm{~min}$. In between incubations the tubes were kept on ice. The extracts were 
either directly used as templates for polymerase chain reaction (PCR) or stored at $-20^{\circ} \mathrm{C}$. To obtain the LSU rDNA sequences, PCR was performed in a nested procedure with the SSUmAf-LSUmAr and the SSUmCf-LSUmBr primer pairs for the first and second nested PCR, respectively (Krüger et al., 2009). The final concentration of the master mix contained 0.6 U Taq polymerase (GE Healthcare, Glattbrugg, Switzerland), $2 \mathrm{mM} \mathrm{MgCl}_{2}, 0.2 \mu \mathrm{M}$ of each primer, $0.125 \mathrm{mM}$ of each deoxynucleotide and $5 \mu \mathrm{g}$ BSA (Bioconcept, Allschwil, Switzerland). Thermal cycling was done in the T3 Thermocycler with the following conditions for the first PCR: 3 min initial denaturation at $95^{\circ} \mathrm{C}$; 35 cycles of $30 \mathrm{~s}$ denaturation at $95^{\circ} \mathrm{C}, 90 \mathrm{~s}$ annealing at $60^{\circ} \mathrm{C}, 2$ min elongation at $72^{\circ} \mathrm{C}$ and 10 min at $72^{\circ} \mathrm{C}$ for final elongation. The same conditions were used for the nested PCR except that the annealing temperature was $63^{\circ} \mathrm{C}$. The PCR products were visualized on $1.5 \%$ agarose gels with $1 \times \mathrm{TAE}$ buffer and $1 \times$ Midori green for staining (NIPPON Genetics EUROPE GmbH, Dueren, Germany). The PCR products with the expected-size bands of 1,500 bp were purified with the High Pure PCR Product Purification Kit (Roche Diagnostics GmbH, Mannheim, Germany) following the manufacturers' protocols. PCR products were cloned into pGEM-T Vector system (Promega, Madison Wisconsin) and the clones were transformed into competent JM109 Escherichia coli cells (Promega, Madison Wisconsin) following the manufacturers' protocols. Ten positive clones from each single spore were confirmed with direct colony PCR technique using the universal M13F and M13R vector primers and purified with ExoSAP-IT (GE Healthcare, Glattbrugg, Switzerland). For sequencing of amplified clones the BigDye Terminator Cycle Sequencing Kit and the ABI3500 were used (Applied Biosystems, Foster City, California). Sequencing primers for the respective samples were the universal vector primers mentioned above in addition to ITS4 and ITS3 primers (White et al., 1990). The electropherograms were processed and analyzed with ChromasPro Version 1.5 (http://www.technelysium.com.au).

The Glomeromycotan origin of the sequences was initially tested by BLAST search. Sequences from the present study were aligned in PAUP* $4 \mathrm{~b} 10$ (Swofford, 2001) to those sequences from GenBank which showed high similarity to them, in addition to all available sequences for other species in their genera. The phylogenetic tree was inferred using maximum likelihood criteria as implemented in PAUP*. Sequences generated in this study were registered in GenBank under the accession numbers JQ287625 to JQ287641. The taxonomic nomenclature recently proposed by Redecker et al. (2013) was used for the species description of AMF.

\section{Results and discussion}

\subsection{Taxonomy}

Morphological and molecular phylogenetic analyses (Figs. 2 and 3) consistently confirmed the affiliations of the fungal strains recovered in one or more of the three desert sites studied and presented here, to four species of AMF. They were identified as Claroideoglomus drummondii, Diversispora aurantia, Diversispora spurca and Funneliformis africanum, clearly differing from each other and from other known species of AMF with glomoid spores and closely related in both morphology and molecular phylogeny.

Our two single spore-isolates of Claroideoglomus drummondii were clearly recognized morphologically by their yellow-colored, small spores and the innermost spore wall layer 3, which usually stains intensively in Melzer's reagent (Figs. 2a and b) (Błaszkowski et al., 2006). C. walkeri, the closest molecular phylogenetic relative of $C$. drummondii, produces white or much lighter spores (Błaszkowski et al., 2006). Sequences from spores from two cultures (F41 and F72) of our collection of C. drummondii were clustered as a sister group to both $C$. drummondii (96\% sequence similarity) and C. walkeri (94\% sequence similarity) with a clearly shorter distance to $C$. drummondii.

Two of our single spore isolates belonged to Diversispora aurantia. The most distinct morphological feature of this species is the deep orange to golden yellow color of its spores, their smooth surface and their relatively thick, coriaceous sensu Walker (1986), innermost spore wall layer 3 (Figs. 2c and d) (Błaszkowski et al., 2004). These render the spores of $D$. aurantia unique among species of AMF with glomoid colored spores of a 3-layered spore wall, of which layer 3 is flexible to semi-flexible (Błaszkowski, 2012). Sequences from two cultures (G5 and I76) of $D$. 


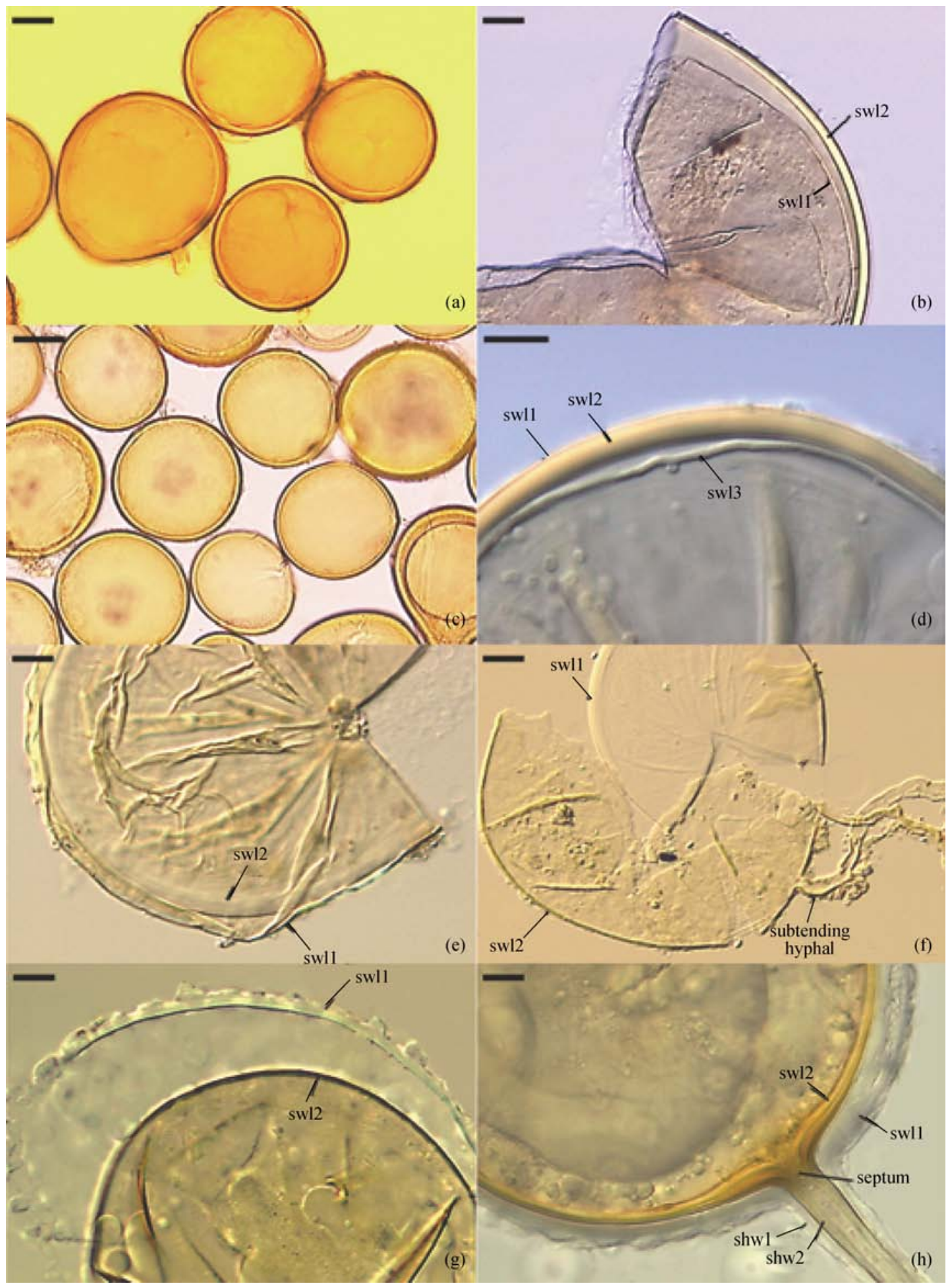

Fig. 2 Morphological characteristics of the spores. (a, b) Claroideoglomus drummondii. (a) Intact spores. (b) Laminate spore wall layer 2 (swl2) and flexible swl3 stained intensively in Melzer's reagent. Swl1 is completely sloughed in this spore. (c, d) Diversispora aurantia. (c) Intact orange spores. (d) Swl1-3; note the thick, coriaceous swl3 separated from laminate swl2. (e, f) Diversispora spurca. (e) Crushed spore with clearly separated swl1 and swl2. (f) Swl1 continuous with the main subtending hyphal wall layer 1 completely separated from swl2 in crushed spore. (g, h) Funneliformis africanum. (g) Separated swl1 and 2 in crushed spore. (h) Swl1 and 2 continuous with subtending hyphal wall layers (shwl)1 and 2 and septum in the lumen of subtending hypha; $(\mathrm{g}, \mathrm{h}$ ) note the much thicker swl1 than swl2. (a, c) Spores in lactic acid. (d, g, h) Spores in PVLG. (e, f) Spores in PVLG+Melzer's reagent. (a-h) differential interference microscopy. Scale bars: $\mathrm{a}, \mathrm{f}=20 \mu \mathrm{m}, \mathrm{c}=50 \mu \mathrm{m}, \mathrm{b}, \mathrm{d}, \mathrm{e}, \mathrm{g}, \mathrm{h}=10 \mu \mathrm{m}$. 


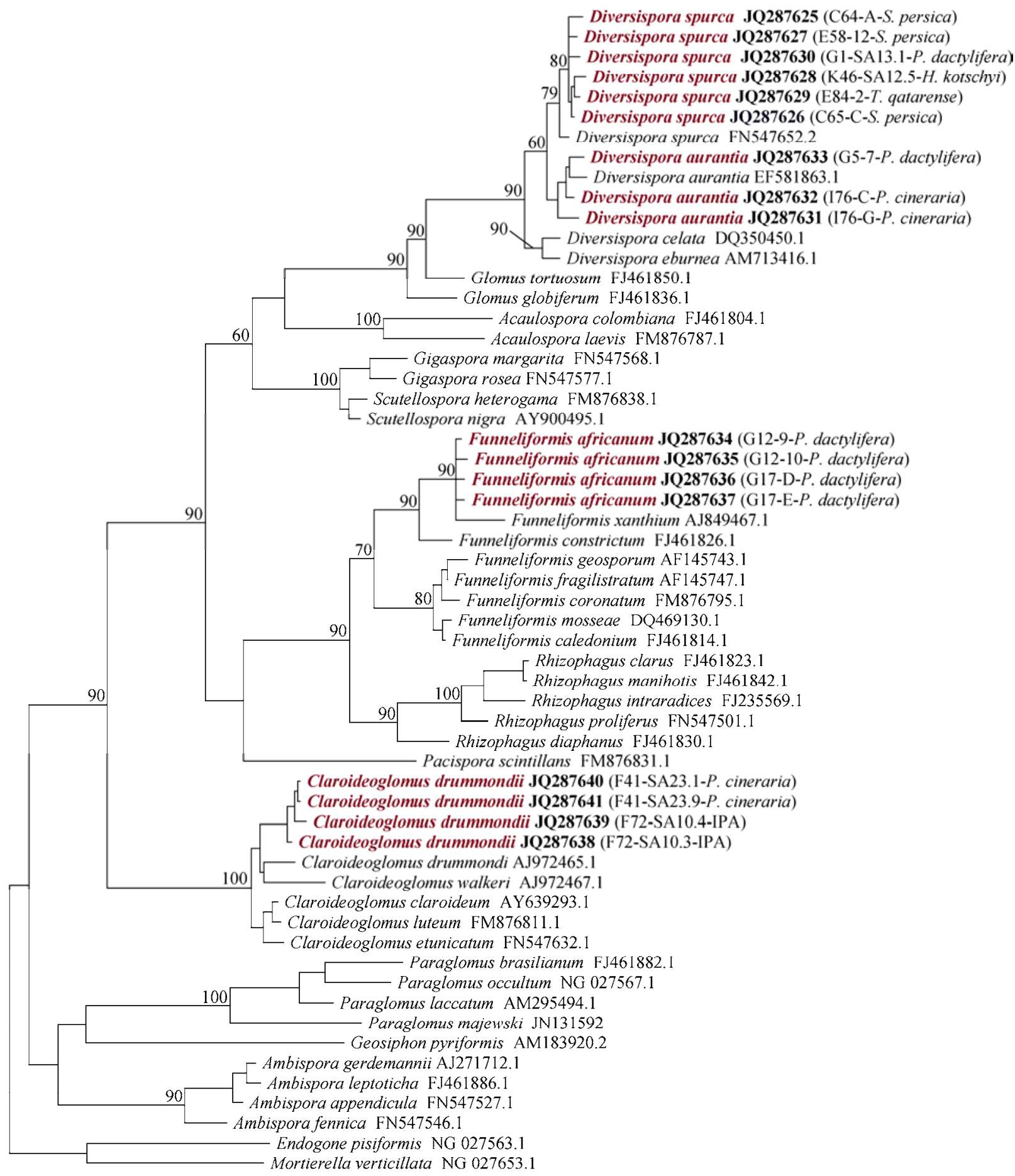

-0.01 substitutions/site

Fig. 3 Phylogenetic tree (maximum likelihood) was inferred from the partial LSU rDNA region (628 dataset characters), showing the positions of the four isolated species of AMF. The sequences obtained from these species are shown in coloured boldface followed by the GenBank accession number. The labels between the brackets indicate the isolate, clone code and either the likely host plant or the interspersed patch of dry grasses (IPA) from where the isolate was obtained. Values associated with branches are bootstrap values of maximum likelihood (100 replicates) as percentages. Only bootstraps above $50 \%$ are included. 
aurantia cluster together with a sequence of this species (96\% sequence similarity) (Fig. 3). Diversispora spurca spores are clearly distinct morphologically because their spore wall layer 1 , which is loosely associated with a laminate spore wall layer 2 , is continuous with subtending hyphal wall layer 1 , being the main structural component of the subtending hyphal wall (Figs. 2e and f) (Pfeiffer et al., 1996; Kennedy et al., 1999; Błaszkowski, 2003). Subtending hyphal wall layer 2, continuous with spore wall layer 2, is present only closely at the spore base and hence it barely touches layer 1 of the subtending hypha. Consequently, in crushed spores the subtending hypha usually detaches along with spore wall layer 1 from the structural spore wall layer 2, forming the main extraradical body of the fungus (Fig. 2f). This phenomenon does not occur in any of the two other known Diversispora spp. and other described species of AMF with glomoid spores (Błaszkowski, 2012). Six different isolates (G64, E58, G1, K46, E84 and C65) showed these morphological characteristics. As it is shown in the phylogenetic tree (Fig. 3), they were all closest to $D$. spurca based on ribosomal LSU-based phylogeny (95\% sequence similarity).

Two of our isolates belonged to Funnelliformis africanum. Among so far recognized species forming colored spores with two spore wall layers, F. africanum is unique, because only its structural laminate spore wall layer 2 is thinner than the sloughing spore wall layer 1, forming the spore surface (Figs. $2 \mathrm{~g}$ and $\mathrm{h}$ ) (Błaszkowski et al., 2010). Its closest phylogenetic relative, as indicated in our analyses of sequences of the LSU rDNA region (Fig. 3), F. xanthium, differs clearly in spore color and size (much lighter and larger, respectively, in $F$. africanum), the number of spore wall layers (2 vs. 3 in F. xanthium), their phenotypic characters (e.g. layer 1 , forming the spore surface, is much thicker and less persistent than that of $F$. xanthium), and features of the spore subtending hypha (Błaszkowski et al., 2004, 2010). However, as results from phylogenetic analyses of sequences of the SSU region of rDNA (Błaszkowski et al., 2010 and our data not shown), F. africanum is closest to F. constrictum, which also differs much in spore color, the phenotypic characters of spore wall components and features of the spore subtending hypha (Trappe, 1977; Błaszkowski, 2003, 2012).

\subsection{Global and local distribution}

Based on the previous literature review, all the species described here, except for $D$. aurantia, have a worldwide distribution. They were recorded from different sites in Asia, Europe and the Americas (Trappe, 1977; Pfeiffer et al., 1996; Kennedy et al., 1999; Błaszkowski, 2003, 2012; Błaszkowski et al., 2006, 2010). The occurrence of $D$. aurantia is likely restricted to regions with warm climate. Of the 6,000 examined rhizosphere soils coming from different regions of the world, this species has never been found in its northern parts (Błaszkowski et al., 2004; Błaszkowski, 2012; Błaszkowski, unpublished data). Pirozynski (1968) concluded that temperature is the major climatic factor determining the distribution and occurrence of fungi in general.

In this study, $D$. aurantia was recovered at two sites, the date palm plantation (P. dactylifera) and the natural undisturbed site (P. cineraria) while $F$. africanum and $C$. drummondii were recovered only at a single site, the date palm plantation and the undisturbed natural site (P. cineraria and IPA), respectively. $D$. spurca was, interestingly, recovered at all the three contrasting sites and was associated with the five different plants in these sites, making it a possibly generalist species in the area. This might be due to its ability to survive and function under contrasting soil conditions and different host plants in addition to its apparent ability to cope with the agricultural practices in the date palm plantation.

\subsection{Importance of the isolated species}

AMF are potential biotechnological tools (AzcónAguilar and Barea, 1997; Gianinazzi et al., 2002; Koltai, 2010) to be used as biofertilizers for sustainable agriculture (Siddiqui et al., 2008) and in re-vegetation programs, especially for endangered plants (Bothe et al., 2010) and desertified ecosystems (Requena et al., 2001). A high potential for success was obtained when AMF were introduced to sites resembling the site of their origin (Caravaca et al., 2003; Calvente et al., 2004; Marulanda et al., 2007; Shen and Wang, 2011).

It has been suggested that AMF of the same species originating from contrasting climatic conditions are functionally diverse suggesting ecotypic differentiation (Antunes et al., 2011) and that fungi exhibit opti- 
mal performance within the range of temperature resembling their original climate (López-Gutiérrez et al., 2008). Such a population differentiation has also been found to result from salinity stress (Carvalho et al., 2004) and edaphic nutrient availability (Johnson et al., 2010). It is reasonable then to propose that our isolated species belong to populations exhibiting unique traits and physiological properties adapted to withstand the extreme desert conditions such as desiccation in long drought seasons, hot summer temperatures and low soil nutrients. Therefore, these species represent good candidates to be used as biofertilizers to enhance crop productivity and the fitness and survival of native plants in soil revegetation and reclamation measures under the environmental conditions prevailing in the Arabian Peninsula and, perhaps, other similar regions. However, functional studies under different arid land conditions and stresses are still needed to verify the physiological adaptability of our species to such conditions.

A prerequisite for the application of AMF as biofertilizers in agriculture and landscaping (Koltai, 2010) is the availability of mass production procedures for the selected strains of AMF and of suitable, preferentially locally available carriers (Sreenivasa and Bagyaraj, 1988; Barea et al., 1993; Kapulnik et al., 1994; Douds et al., 2006). Moreover, a strict quality control is essential including methods for ascertaining the absence of infestations with soil-borne pathogens and, preferentially, for assessing the performance of the inoculated AMF in the field.

In Oman, where we identified this collection of potentially desert-adapted strains of AMF, there is a great effort to preserve the country's natural vegetation (Patzelt et al., 2008; Pickering and Patzelt, 2008). Mycorrhizal biotechnology might be a crucial factor to overcome difficulties met in propagation and maintenance of some indigenous plants (Patzelt et al., 2008).

\section{Conclusions}

The four described species in this paper are recorded for the first time in the whole Arabian Peninsula and, thus, expand the species number currently known to occur in this arid region (Khaliel, 1989; Al-Yahya'ei et al., 2011). Because some of our isolates come from extremely arid environments, these AMF may be an asset to biodiversity conservation in desert areas, particularly in the Arabian Peninsula. They may also open the door for basic research regarding functional characterization, as well as for applied research in view of their use as biofertilizers to promote sustainable agriculture under arid conditions.

\section{Acknowledgments}

The study was financed by the Oman's Ministry of Agriculture and Fisheries, the University of Basel, the Polish National Centre of Science (N N304 061739 and DEC-2012/05/B/NZ8/ 00498) and the Swiss National Science Foundation (130794 to A.W.). We thank Paola BONFANTE and her team (University of Torino, Italy) for their supportive role during the initiation of the AM fungal diversity studies in southern Arabia; Ahmad AL-BAKRI, the Director General of Agricultural and Livestock Research of Oman's Ministry of Agriculture and Fisheries for providing formal and logistical support; Hamood AL-HASHMI for his assistance during the sampling trips; Annette PATZELT, Oman Botanic Garden for the plant identification.

\section{References}

Al-Yahya'ei M N, Oehl F, Vallino M, et al. 2011. Unique arbuscular mycorrhizal fungal communities uncovered in date palm plantations and surrounding desert habitats of Southern Arabia. Mycorrhiza, 21(3): 195-209.

Antunes P M, Koch A M, Morton J B, et al. 2011. Evidence for functional divergence in arbuscular mycorrhizal fungi from contrasting climatic origins. New Phytologist, 189(2): 507-514.

Augé R M. 2001. Water relations, drought and vesicular-arbuscular mycorrhizal symbiosis. Mycorrhiza, 11(1): 3-42.

Azcón-Aguilar C, Barea J M. 1997. Applying mycorrhiza biotechnology to horticulture: significance and potentials. Scientia Horticulturae, 68: $1-24$.

Barea J M, Azcón R, Azcón-Aguilar C. 1993. Mycorrhiza and crops. In: Tommerup I. Advances in Plant Pathology, Vol. 9. Mycorrhiza: A Synthesis. London: Academic Press, 167-189.

Błaszkowski J. 2003. Arbuscular mycorrhizal fungi (Glomeromycota), Endogone and Complexipes species deposited in the Department of Plant Pathology, University of Agriculture in Szczecin, Poland. http://www.agro.ar.szczecin.pl/ jblaszkowski/.

Błaszkowski J, Blanke V, Renker C, et al. 2004. Glomus aurantium and G. xanthium, new species in Glomeromycota. Mycotaxon, 90(2): 447-467.

Błaszkowski J, Czerniawska B. 2006. The occurrence of arbuscular mycorrhizal fungi of the phylum Glomeromycota in Israeli soils. Acta Societatis Botanicorum Poloniae, 75(4): 339-350.

Błaszkowski J, Renker C, Buscot F. 2006. Glomus drummondii and G. walkeri, two new species of arbuscular mycorrhizal fungi (Glomeromycota). Mycological Research, 110(5): 555-566.

Błaszkowski J, Kovács G M, Balázs T, et. al. 2010. Glomus africanum 
and G. iranicum, two new species of arbuscular mycorrhizal fungi (Glomeromycota). Mycologia, 102(6): 1450-1462.

Błaszkowski J. 2012. Glomeromycota. Kraków: Polish Academy of Sciences.

Bothe H, Turnau K, Regvar, M. 2010. The potential role of arbuscular mycorrhizal fungi in protecting endangered plants and habitats. Mycorrhiza, 20(7): 445-457.

Calvente R, Cano C, Ferrol N, et al. 2004. Analysing natural diversity of arbuscular mycorrhizal fungi in olive tree (Olea europaea L.) plantations and assessment of the effectiveness of native fungal isolates as inoculants for commercial cultivars of olive plantlets. Applied Soil Ecology, 26(1): 11-19.

Caravaca F, Barea J M, Palenzuela J, et al. 2003. Establishment of shrub species in a degraded semiarid site after inoculation with native or allochthonous arbuscular mycorrhizal fungi. Applied Soil Ecology, 22(2): 103-111.

Carvalho L M, Correia P M, Martins-Loucao M A. 2004. Arbuscular mycorrhizal fungal propagules in a salt marsh. Mycorrhiza, 14(3): 165-170.

Cui M, Nobel P S. 1992. Nutrient status, water uptake and gas exchange for three desert succulents infected with mycorrhizal fungi. New Phytologist, 122(4): 643-649.

Daniels B A, Skipper H D. 1982. Methods for the recovery and quantitative estimation of propagules from soil. In: Schenck N C. Methods and Principles of Mycorrhizal Research, Minnesota: The American Phytopathological Society, 29-35.

Douds D D, Nagahashi G, Pfeffer P E, et al. 2006. On-farm production of AM fungus inoculum in mixtures of compost and vermiculite. Bioresource Technology, 97(6): 809-818.

Fisher M, Membery D A. 1998. Climate. In: Fisher M, Membery D A. Geobotany: Vegetation of the Arabian Peninsula. Dordrecht: Kluwer Academic Publishers, 5-38.

Gianinazzi S, Schüepp H, Barea J M, et al. 2002. Mycorrhizal Technology in Agriculture, from Genes to Bioproducts, Basel. Switzerland: Birkhäuser Verlag.

Glennie K W, Singhvi A K. 2002. Event stratigraphy, paleoenvironment and chronology of SE Arabian deserts. Quaternary Science Reviews, 22(7): 853-869.

Jacobson K M. 1997. Moisture and substrate stability determine VA-mycorrhizal fungal community distribution and structure in an arid grassland. Journal of Arid Environments, 35(1): 59-75.

Johnson N C, Wilson G W T, Bowker M A, et al. 2010. Resource limitation is a driver of local adaptation in mycorrhizal symbioses. Proceedings of the National Academy of Sciences of the United States of America, 107(5): 2093-2098.

Kapulnik Y, Heuer B, Patterson N A, et al. 1994. Stunting syndrome in peanuts and agronomic approaches for its release. Symbiosis, 16(3): 267-278.

Kennedy L J, Stutz J C, Morton J B. 1999. Glomus eburneum and G. luteum, two new species of arbuscular mycorrhizal fungi, with emendation of G. spurcum. Mycologia, 91(6): 1083-1093.

Khaliel A S. 1989. Mycorrhizal status of some desert plants and correlation with edaphic factors. Nippon Kingakukai Kaiho, 30(2): 231-238.
Kiran B, Rao A V, Tarafdar J C. 1989. Occurrence of VAM associations in different plant species of the Indian desert. Arid Soil Research and Rehabilitation, 3(3): 391-396.

Koltai H. 2010. Mycorrhiza in floriculture: difficulties and opportunities. Symbiosis, 52: 55-63.

Krüger M, Stockinger H, Krüger C, et al. 2009. DNA-based species level detection of Glomeromycota: one PCR primer set for all arbuscular mycorrhizal fungi. New Phytologist, 183(1): 212-223.

López-Gutiérrez J C, Malcolm G M, Koide R T, et al. 2008. Ectomycorrhizal fungi from Alaska and Pennsylvania: adaptation of mycelial respiratory response to temperature? New Phytologist, 180(4): 741-744.

Marulanda A, Porcel R, Barea J M, et al. 2007. Drought tolerance and antioxidant activities in lavender plants colonized by native drought-tolerant or drought-sensitive Glomus species. Microbial Ecology, 54(3): 543-552.

Mathur N, Vyas A. 1995. Mycorrhizal dependency of Prosopis cineraria in Indian Thar desert. Indian Journal of Forestry, 18(4): 263-266.

Mathur N, Singh J, Bohra S, et al. 2006. Increased nutrient uptake and productivity of Plantago ovata Forssk by AM fungi under field conditions. American-Eurasian Journal of Scientific Research, 1: 38-41.

Neumann E, George E. 2004. Colonisation with the arbuscular mycorrhizal fungus Glomus mosseae (Nicol. \& Gerd.) enhanced phosphorus uptake from dry soil in Sorghum bicolor (L.). Plant and Soil, 261: 245-255.

Newsham K K, Fitter A H, Watkinson A R. 1995. Multi-functionality and biodiversity in arbuscular mycorrhizas. Trends in Ecology \& Evolution, 10: 407-411.

Omar M B, Bollan L, Heather W A. 1979. A permanent mounting medium for fungi. Bulletin of the British Mycological Society, 13: 31-32.

Panwar J, Vyas A. 2002. AM fungi: A biological approach towards conservation of endangered plants in Thar Desert, India. Current Science, 82(5): 576-578.

Patzelt A, Morris L, Al Harthi L, et al. 2008. The Oman Botanic Garden (1): the vision, early plant collections and propagation. Sibbaldia, 6: 41-77.

Pfeiffer C M, Walker C, Bloss H E. 1996. Glomus spurcum: a new endomycorrhizal fungus from Arizona. Mycotaxon, 59: 373-382.

Pickering H, Patzelt A. 2008. Field Guide to the Wild Plants of Oman. Royal Botanic Gardens. Kew: Kew Publishing.

Pirozynski K A. 1968. Geographical distribution of fungi. In: Ainsworth G C, Sussman A S. The Fungi. New York: Academic Press, 487-504.

Preusser F, Radies D, Matter A. 2002. A 160,000-year record of dune development and atmospheric circulation in Southern Arabia. Science, 296(5575): 2018-2020.

Redecker D, Schüßler A, Stockinger H, et al. 2013. An evidence-based consensus for the clasification of arbuscular mycorrhizal fungi (Glomeromycota). Mycorrhiza, 23(7): 515-531.

Requena N, Pérez-Solís E, Azcón-Aguilar C, et al. 2001. Management of indigenous plant-microbe symbioses aids restoration of desertified ecosystems. Applied and Environmental Microbiology, 67(2): 495-498.

Rillig M C, Mummey D L. 2006. Mycorrhizas and soil structure. New Phytologist, 171(1): 41-53. 
Shen S K, Wang Y H. 2011. Arbuscular mycorrhizal (AM) status and seedling growth response to indigenous AM colonisation of Euryodendron excelsum in China: implications for restoring an endemic and critically endangered tree. Australian Journal of Botany, 59(5): 460-467.

Shi Z Y, Zhang L Y, Li X L, et al. 2007. Diversity of arbuscular mycorrhizal fungi associated with desert ephemerals in plant communities of Junggar Basin, northwest China. Applied Soil Ecology, 35(1): 10-20.

Siddiqui Z A, Akhtar M S, Futai K. 2008. Mycorrhizae: Sustainable Agriculture and Forestry. Dordrecht: Springer.

Smith S E, Read D J. 2008. Mycorrhizal Symbiosis. $3^{\text {rd }}$ ed. San Diego: Academic Press.

Sreenivasa M N, Bagyaraj D J. 1988. Selection of a suitable substrate for mass multiplication of Glomus fasciculatum. Plant and Soil, 109(1): 125-127.

Stutz J C, Copeman R, Martin C A, et al. 2000. Patterns of species composition and distribution of arbuscular mycorrhizal fungi in arid regions of southwestern North America and Namibia, Africa. Canadian Journal of Botany, 78(2): 237-245.

Swofford D L. 2001. PAUP*. Phylogenetic Analysis Using Parsimony (*and Other Methods). Sunderland: Sinauer Associates.
Tchabi A, Coyned D, Hountondji F, et al. 2010. Efficacy of indigenous arbuscular mycorrhizal fungi for promoting white yam (Dioscorea rotundata) growth in West Africa. Applied Soil Ecology, 45(2): 92-100.

Trappe J W. 1977. Three new Endogonaceae: Glomus constrictus, Sclerocystis clavispora, and Acaulospora scrobiculata. Mycotaxon, 6(2): 359-366.

Uhlmann E, Görke C, Petersen A, et al. 2006. Arbuscular mycorrhizae from arid parts of Namibia. Journal of Arid Environments, 64(2): 221-237.

UNEP. 2006. Global Deserts Outlook. United Nations: United Nations Environmental Programme.

Walker C. 1986. Taxonomic concepts in the Endogonaceae. II. A fifth morphological wall type in endogonaceous spores. Mycotaxon, 25(1): 95-99.

White T J, Bruns T, Lee S, et al. 1990. Amplification and direct sequencing of fungal ribosomal RNA genes for phylogenetics. In: Innis M A, Gelfand D H, Sninsky J J, et al. PCR Protocols: A Guide to Methods and Applications, New York: Academic Press, 315-322.

Zhang T, Sun Y, Song Y, et al. 2011. On-site growth response of a desert ephemeral plant, Plantago minuta, to indigenous arbuscular mycorrhizal fungi in a central Asia desert. Symbiosis, 55(2): 77-84. 